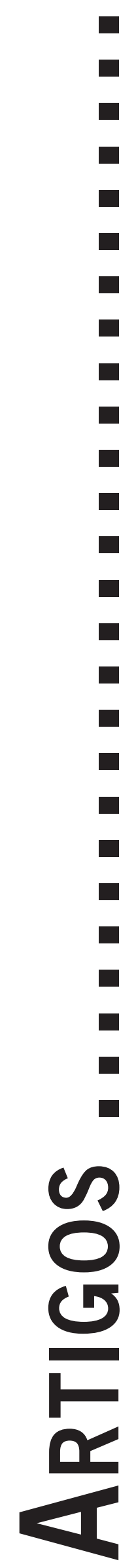




\title{
GESTALT-TERAPIA E O DIÁLOGO PSICOLÓGICO NO HOSPITAL: UMA REFLEXÃO
}

\author{
The Gestalt Therapy and Psychological Dialogue In The Hospital: A Reflection
}

La Terapia-Gestalt y el Diálogo Psicologico en el Hospital: Una Reflexión

JoANNELIESE DE LUCAS Freitas

NutTy NADIR StRoieK

DÉBORA BOTIN

\begin{abstract}
Resumo: O objetivo do presente artigo é apresentar uma reflexão sobre a psicologia da saúde e hospitalar tendo como referencial teórico a Gestalt-terapia. Entende-se o diálogo psicológico (Eu-Tu/Eu-Isso) como suporte para uma prática hospitalar humanizada e como elemento ontológico do contato. Esta proposta contrapõe-se ao modelo biomédico vigente no qual a lógica do pensar científico regula as vivências humanas, decompõe e fragmenta o homem enfraquecendo-o enquanto Ser. A relevância deste tema se apresenta por ser a Gestalt-terapia, assim como a psicologia da saúde e hospitalar, áreas de conhecimento recentes e em crescente desenvolvimento na atualidade. Destaca-se o diálogo como elemento fundamental da atuação do psicólogo nesse campo. Defende-se que o papel do psicólogo hospitalar deve se desenvolver alicerçado no diálogo, destacando-se as atitudes de Inclusão e Presença bem como atenção à dimensão da corporeidade.
\end{abstract}

Palavras-chave: Psicologia Hospitalar; Diálogo; Inclusão; Presença; Corporeidade.

Abstract: The aim of this article is to present a reflection between the hospital and health psychology and gestalt therapy. Such considerations were based on the psychological dialog (I-You/I-It) which pointed to a humanized hospital practice, being dialogue the ontological element of contact. This project oppose to the current biomedical model where the logic of scientific thinking regulates the human existence, decomposes and fragments the man weakening it as an entity. The relevance of this theme is present because the gestalt therapy and the health and hospital psychology are recent knowledge areas in crescent progress today. The working method used was a bibliographic review, with the use of electronic research, as well as the use of books that broach issues of this Article. As a result of this work distinguish the Inclusion, the Presence and Corporeity as key elements of the work of the hospital psychologist.

Keywords: Health Psychology; Dialogical; Inclusion; Presence; Corporeity.

Resumen: El objetivo de este artículo es presentar una observación sobre la psicología de la salud y el hospital teniendo como terapia gestalt teórica. Esta ponderación marcharon desde la comprensión del cuadro de diálogo psicológica (I-tu/yo-esto) como apoyo de una práctica de hospital y como ontológico humanizada el elemento de contacto. Esta preocupaciones de propuesta el modelo biomédico actual donde la lógica del pensamiento científico regula experiencias humanas, se descompone y fragmentos del hombre debilita siendo. La relevancia de este tema presenta por ser la terapia gestalt-, así como la psicología de la salud y hospital, recientes de las áreas de conocimiento y desarrollo de hoy en día. El diálogo como un elemento clave del desempeño del psicólogo en este campo. Sostiene que el papel del psicólogo hospital debe desarrollar desde la Fundación del diálogo, incluyendo las actitudes de inclusión y presencia, así como atención a la escala de bajo construcción.

Palabras-clave: Psicología Hospital; El Diálogo; La Inclusión; La Presencia; Corporeidad.

\section{Introdução}

Há alguma especificidade do trabalho do Gestaltterapeuta no contexto hospitalar? Essa é a pergunta motivadora deste trabalho e que se construiu a partir da experiência das autoras em diferentes contextos de atendimento à saúde, no Distrito Federal e no Paraná.

Apesar de nos Encontros e Congressos nacionais já começarem a despontar trabalhos que refletem sobre o nosso papel nas instituições hospitalares, a produção bibliográfica na área sob o viés da Gestalt-terapia é ainda pequena. Notando tal quadro, buscamos refletir so- bre as possíveis relações entre a psicologia da saúde e a Gestalt-terapia. Por ser uma abordagem com uma compreensão própria da relação terapêutica, uma de suas maiores contribuições talvez seja exatamente apontar elementos no trabalho e postura do psicólogo hospitalar que contribuam para a construção de um vínculo específico. Esta especificidade se foca na capacidade de se produzir um diálogo genuíno em um ambiente tão árido e hostil como o de um hospital geral. Entendemos como de grande relevância tal reflexão, uma vez que a psicologia hospitalar é uma especialização recente e até mesmo tardia da psicologia, e que durante muito tempo foi 
fortemente influenciada pelo modelo biomédico de atuação, à exceção do pioneirismo da perspectiva social de Mary Jane Spink no Brasil.

Dentre as tantas "Psicologias" do mercado de trabalho, a psicologia hospitalar é um nicho entendido como algo novo. Entretanto, desde o final da década de 50 esse campo vem assumindo sua identidade, aprofundando estudos e expandindo suas possibilidades, bem como conquistando seu espaço dentro do reduto do dito saber médico (Lazzaretti, 2007, p. 49).

A Psicologia da Saúde - e mais especificamente a Psicologia Hospitalar -, em seu início seguiu e se identificou com métodos do mainstream psicológico, comportamental e quantitativo. Amplamente, essa área abordou e se filiou a uma perspectiva biomédica ao invés de desenvolver um pensamento crítico em relação a esse modelo. A medicina é uma profissão poderosa no mundo ocidental e no início do trabalho das equipes multiprofissionais sua dominância das práticas era devida, também em parte, à dificuldade de se estabelecer o papel específico de cada membro da equipe e seu lugar em espaços tradicionalmente médicos (Spink, 1992; Murray \& Chamberlain, 1999).

Na década de 1960, os pioneiros - tais como a $\mathrm{Dr}^{\mathrm{a}}$ Matilde Neder, do Hospital das Clínicas de São Paulo -, buscaram na psicologia clínica um modelo de atuação para o atendimento de seus pacientes e geralmente eram solicitados a responder à demanda médica e a "apagar incêndios" ou "segurar a barra" dos doentes, como afirma Spink (1992).

Em entrevista concedida à Revista Prática Hospitalar, Chiattone (2004) afirma ser o Brasil pioneiro mundial na especialidade de psicologia hospitalar, embora a American Psychological Association (APA) tenha sido a primeira a reconhecer a área da saúde como campo oficial de atuação do psicólogo. Em 20 de dezembro de 2000, o Conselho Federal de Psicologia (CFP), por meio da resolução $n^{\circ} 14 / 00$, instituiu, entre outras especialidades, a de especialista em psicologia hospitalar.

Segundo o Conselho Federal de Psicologia (2009), o psicólogo hospitalar tem sua função centrada no âmbito secundário e terciário de atenção à saúde, atuando em instituições de saúde e realizando atividades como: atendimento psicoterapêutico, grupos psicoterapêuticos, grupos de psicoprofilaxia, atendimentos em ambulatório e unidade de terapia intensiva, em pronto atendimento, enfermarias em geral, psicomotricidade no contexto hospitalar, avaliação diagnóstica, psicodiagnóstico, interconsultas e, ainda, atua também por meio de consultoria nestes contextos.

A realidade e o trabalho do psicólogo hospitalar também sofrem influências das políticas públicas de humanização em saúde que tornaram a presença de equipes multidisciplinares obrigatória no atendimento ao doente hospitalizado. A psicologia da saúde e a psicologia hospitalar apresentam perspectivas variadas de teorização e prática, derivadas das mais diversas perspectivas psicológicas: comportamental, social, psicanalítica e fenomenológica. Entretanto, sob o olhar da Gestalt-terapia, consideramos ser necessário uma reflexão mais abrangente. No presente trabalho propomos refletir como o self do terapeuta e o diálogo Eu-Tu podem ser poderosos instrumentos de trabalho do psicólogo hospitalar, assim como já nos é na clínica, quando estamos atentos para suas especificidades.

A Gestalt-terapia é uma abordagem com foco na relação dialógica. O diálogo é por nós entendido como fundamental para a existência humana e característica essencial da relação terapêutica (Freitas, 2009a). No âmbito hospitalar pode, inclusive, ser assumido como instrumento - até mesmo preventivo - frente às dificuldades humanas que o adoecer e a hospitalização podem suscitar no cliente, como por exemplo, o isolamento de suas atividades cotidianas, da família e do seu círculo social, as mudanças de papéis acarretadas pelas limitações e desafios das doenças e seus tratamentos, sem mencionar os desafios do processo intrínseco ao adoecimento físico.

Incluir a dimensão ontológica dos usuários dos serviços de saúde possibilita o resgate da intersubjetividade e da humanização nesse espaço moldado pela impessoalidade de técnicas invasivas e da pretensa neutralidade científica. Em um espaço assim moldado, a existência passa a ser referenciada pela ordem das intervenções hospitalares e não mais pela própria condição do existir (Sant'Anna, 2001; Freitas, 2009b). Uma existência, que destacamos ser vivida corporalmente, embora em um corpo que não é apenas objeto como a medicina por vezes considera e prioriza.

É sabido que com o Renascimento Cultural, especialmente com Descartes, foi permitido um retorno mais intenso à separação entre res cogitans e res extensa. O sagrado abre espaço para o material, com a separação entre o sublime - alma - e o denso e impuro - o corpo. Com esta separação nasce o avanço dos manuais de anatomia, da ciência e da medicina, que vão permitir ao médico tratar a doença e não o doente (Foucault, 2001). Tal separação mantém até hoje a herança de uma atuação em saúde centrada na cura, no hospital e na esfera orgânica ao invés de se pautar em uma atuação preventiva, comunitária e holística ou organísmica.

Apesar de todos os avanços e propostas de humanização e de uma compreensão do homem desde sua totalidade - encontrada na Organização Mundial de Saúde (OMS) e no Sistema Único de Saúde (SUS) brasileiro - no contexto da atuação em saúde é ainda o paradigma cartesiano da separabilidade corpo-mente que tem prioritariamente motivado a atuação profissional, posicionando a existência humana como revelada apenas pela racionalidade, lançando-a para fora das relações humanas (Castro, 2002). Não se trata de negar ou esquecer que o 
usuário dos sistemas de saúde público e privado procura tais serviços por sua condição de adoecimento somático. Entretanto, tal concepção moderna, cartesiana de homem e mundo, que privilegia o contexto da saúde pública como ainda centrado na instituição hospitalar restringe a compreensão do existir humano em sua plenitude e se afasta das concepções contemporâneas que apontam para uma abordagem complexa do humano.

\section{O Contexto do Diálogo no Hospital}

Inspirados na filosofia existencial de Martin Buber (1974; 1982), autores como Hycner e Jacobs (1997) vão refletir sobre a importância da relação dialógica para a constituição do humano e, conseqüentemente, para todas as relações de cuidado em Gestalt-terapia. O diálogo em uma relação psicoterápica se refere ao "contexto relacional total em que a singularidade de cada pessoa é valorizada; relações diretas, mútuas e abertas entre as pessoas são enfatizadas" (Hycner \& Jacobs, 1997, p.30). Mas há especificidades e diferenças relevantes entre o contexto psicoterápico e o contexto hospitalar.

Buscar a construção de uma qualidade de diálogo nas instituições hospitalares é um desafio com dificuldades impostas pelas próprias condições do contexto: as enfermarias que se constituem como espaços públicos, diferente da privacidade dos consultórios particulares, a rotatividade dos pacientes, o pouco e exíguo tempo de contato, delimitado pelo tempo de internação ou de espera, conflitante com o tempo indeterminado dos processos terapêuticos tradicionais, e as infindáveis intervenções médico-hospitalares entremeando a relação como um conta-gotas infinito. Não são raras as vezes em que a intervenção ou apenas uma visita ao paciente ocorre em meio a interferência de outros pacientes, familiares, equipe, o que exige do profissional uma compreensão desse contexto como sendo sua condição relacional e singular naquele momento, determinado pela rotina hospitalar e pela patologia e suas conseqüências. O papel do psicólogo nesse contexto não é o do psicoterapeuta em um sentido estrito, apesar de defendermos a possibilidade do investimento em uma qualidade relacional que o Gestaltterapeuta procura exercer em sua prática.

Diante da despersonalização sofrida na instituição hospitalar, estar presente para um paciente e incluirse em sua existência exige que o foco do trabalho esteja centrado na possibilidade do restabelecimento da sua autonomia e do seu bem-estar frente à sua condição. Esta nova, por vezes transitória, condição é permeada pela dor, mal-estar e frequentemente, pelo medo, pela ameaça de mutilação ou de interrupção de projetos de vida. Essas são condições existenciais delimitadoras do contexto da atuação em saúde com as quais o psicólogo hospitalar deve estar preparado para lidar.

Segundo Freitas (2009b, p. 87)
(...) dentro de uma perspectiva da Gestalt-terapia, todos estes elementos devem ser compreendidos como mundo, condição existencial do contexto relacional. Assim sendo, todas estas diferenças, interrupções, vínculos, podem ser trabalhados como abertura para novas significações, mediante a problematização de tais conflitos dentro do como o paciente se apresenta.

Além das dificuldades impostas pelo contexto, a busca ou o estabelecimento de uma relação terapêutica em função de uma atitude dialógica pelo psicólogo não determina necessariamente a ocorrência do diálogo:

Ao abordarmos o outro com uma atitude Eu-Tu, não temos a garantia de que um encontro mútuo Eu-Tu irá se desenrolar. Posso me aproximar da outra pessoa com uma atitude genuinamente aberta à possibilidade de que tal movimento ocorra. No entanto, ele só poderá ocorrer se o outro disser 'sim' a minha aproximação (Hycner \& Jacobs, 1997, p. 104).

No contexto da intervenção hospitalar, assim como na psicoterapia, o diálogo se constitui a partir da possibilidade da existência da relação mútua entre psicólogo e paciente. $\mathrm{O}$ que constitui o próprio diálogo, por conseguinte, não é a fala. O que comunica é a relação Eu-Tu. Ela pode acontecer simplesmente pelo silêncio, se constituindo não pela expressão da voz e sim pelo contato. Diálogo é, destarte, contato (Hycner, 1995; Freitas, 2009a).

O diálogo, portanto, se mostra como fenômeno do "entre", do espaço e do campo relacional (Hycner, 1995; Freitas, 2009a). Para o estabelecimento do diálogo são necessários dois elementos fundamentais, explorados por Hycner (1995) que vamos contextualizar aqui no trabalho em saúde, a saber, a presença e a inclusão.

Aliado a estes elementos, apresentamos o corpo como elemento fundamental da relação dialógica. Segundo Freitas (2009a) o diálogo ocorre em dois níveis diferentes: no da corporeidade e no nível da fala. "O corpo é, portanto, fundo da expressão”, espaço da realização do contato. Sendo o corpo "fundo", é o lugar das intersecções, é campo, é ponto de contato e encontro entre paciente e psicólogo. Nada mais significativo quando o ponto central ou de partida da relação é justamente o adoecimento somático. Ao constatarmos que o corpo é elemento essencial do diálogo é necessário compreender o que chamamos de corpo e como este se constitui enquanto dimensão dialógica.

\section{Corpo e Diálogo}

Segundo uma perspectiva fenomenológica, assim como da Gestalt-terapia - que concebe o homem como totalidade -, o corpo deve ser apreendido não mais como 
objeto, mas, como perspectiva do mundo, em que o corpo não se torna completamente objeto do mundo, senão seu meio de comunicação com este (Freitas, 2005, 2009a).

Para a fenomenologia o corpo não é algo que eu tenho, mas que eu sou (Merleau-Ponty, 1994). Por isso, no contato com o outro, eu me exponho por meio de gestos, atitudes, mímicas, olhares, lágrimas, pelo sorriso e por tantos outros gestos e expressões faciais. Tais gestos expressivos não são da ordem apenas corporal, mas da ordem do sujeito que é corpo, do corpo como campo expressivo. Dito de outra forma: numa compreensão organísmica, "do ponto de vista psicológico o corpo se apresenta como espaço de expressão subjetiva e lugar de organização de novos sentidos que apontam para a existência humana" (Freitas, 2005, p. 35).

A medicina tradicional e mesmo a psicossomática revelam um corpo como um objeto a ser compreendido e, quando muito, apenas espaço de uma realidade psicológica outra, separada e ali representada, embora distante daquela corporal e material O corpo doente não é apenas um organismo acometido de infecções ou patologias, mas é um corpo experienciado por um doente, como um doente, dotado de uma função na relação desse sujeito com o mundo, mas que, apesar de estar doente, é também um corpo com história e com perspectivas. Isso é, um corpo que carrega sentidos subjetivos que tem relações íntimas com a própria história da pessoa, com seus contextos de vida e com os recursos de que dispõe para lidar com a doença.

Assim sendo, diferentemente do médico, o psicólogo da saúde não trabalha com o corpo biológico, mas com o corpo vivido, que é uma história, um nó significativo, como nos diria Merleau-Ponty (1994). Deste modo, como psicólogos inseridos no contexto da saúde, devemos todo tempo nos questionar sobre como estas dimensões interagem na significação da existência e na configuração da subjetividade no aqui e agora da internação, do adoecimento, da eminência da cirurgia ou até mesmo da morte.

O diálogo Eu-Tu enquanto encontro existencial entre duas pessoas se distancia da relação Eu-Isso, característica da atuação biomédica, na qual o corpo perde essa condição existencial de campo expressivo e passa a ser figura destacada de seu fundo de subjetividade. Por se constituir como um campo expressivo, o diálogo pode se configurar por meio de gestos e comunicações não-verbais, recursos indispensáveis quando no trato de doentes inseridos no contexto dos leitos do hospital e com os quais o psicólogo diariamente necessita se relacionar.

O ponto de partida é a sua existência fragilizada e debilitada pelo adoecimento. O psicólogo hospitalar deve intervir com foco na abertura de possibilidades do paciente, em sua atual configuração existencial, seu processo do existir nesse contexto específico que é permeado pelo comprometimento somático ou que derivam deste.

\section{Presença e Inclusão}

A presença é uma atitude do psicólogo na qual este se revela como uma pessoa autêntica. É estar na relação abrindo-se existencialmente para que o outro possa se apoiar em seu self como caminho de autopercepção. A presença não significa simplesmente uma forma de estar com o outro na qual não deva existir interferência de considerações ou reservas. A presença é um estar consciente de si para e na relação. Ela é fundamental uma vez que o paciente hospitalizado se encontra em constante confronto com seu self, seja por sua doença ou mesmo pela situação existencial na qual se encontra.

O psicólogo hospitalar tem como função desempenhar o papel de facilitador e promover o diálogo utilizando-se da presença, que em seu desenvolvimento fixa-se em fazer com que o paciente se perceba dentro de novas possibilidades. É como se, por meio da presença, o paciente pudesse fazer uso do self do terapeuta para perceber a si próprio. Essa forma de abordagem é mencionada por Yontef (1998) como diálogo horizontal, que é o ato de "se chegar ao centro da existência que o paciente esta vivendo" (Yontef, 1998, p. 259).

Segundo Hycner (1995), presença "é a consciência que se dirige completamente ao 'processo de existir' da outra pessoa. Isso requer que o terapeuta esteja atento à experiência do cliente, mas atento também a sua própria experiência" (p. 114), em nosso caso, atento a sua própria experiência humana de contato íntimo e cotidiano com a dor, com a morte e a limitação. É estar aware de si na relação com o outro; e estar voltado atentamente à experiência do outro nos conduz à inclusão.

Na inclusão há uma busca por posicionar-se na experiência do cliente, sem julgar, analisar ou interpretar. Tal atitude facilita a ressignificação de sua condição existencial e de sua conscientização, abre a possibilidade da auto-aceitação quanto a sua experiência frente ao desconhecido, à dependência de uma equipe, às (im) possibilidades de tratamento e às limitações que possa vivenciar advindas de sua patologia e hospitalização. Na tarefa de atuar no contexto institucional como um todo seria de grande valia a reflexão e o estudo de tais atitudes junto à família e à equipe, uma vez que o trabalho do psicólogo hospitalar não se restringe ao acompanhamento dos pacientes, mas em todo o contexto do processo saúde-doença. Trabalhar as expectativas, sofrimentos, desejos e limitações da família e da equipe também se constituem como parte fundamental do trabalho do psicólogo hospitalar, sem entrarmos no mérito da atuação em saúde nem tampouco dos contextos sociais e comunitários de prevenção, também carentes de reflexões em Gestalt-terapia.

Hycner (1995) afirma que a inclusão é necessária para a existência de uma relação dialógica genuína, um movimento de "ir-e-vir", onde o psicólogo 
(...) precisa ser capaz de, tanto humanamente quanto possível, tentar experienciar o que o cliente está experenciando do seu lado do diálogo. Na melhor das hipóteses, é apenas uma experiência momentânea, pois ninguém pode manter uma atitude desse tipo durante muito tempo (...). Há uma experiência de ausência de self nesses momentos (p. 42).

O self do terapeuta passa a ser fundo para que a existência do paciente seja figura. Em seu campo, significa emprestar sua existência e sua corporeidade para permitir que o estranhamento do sentido do outro encontre espaço de expressão na existência atual do terapeuta (Freitas, 2009a). Diferente da empatia, a inclusão é um voltar-se “(...) existencialmente para o outro e uma tentativa de experienciar o lado da pessoa assim como o próprio" (Hycner, 1995, p. 44). É permitir ao outro ser ele mesmo enquanto Tu.

Na teoria da Gestalt-terapia é salientada a importância ôntica do contato. Tal forma específica de contato que é o diálogo torna-se a base para a autorrealização. Quando possibilita a awareness integrativa, permite ao paciente, à família ou à equipe responder a uma situação de forma apropriada às suas necessidades e às possibilidades da situação que o contexto possa apresentar (Hycner \& Jacobs, 1997).

Sabemos que a Gestalt-terapia defende que para viver essa integração a pessoa não deve julgar sua experiência nem desprezar ou alienar aspectos de si mesma. Isso inclui seus sentimentos, o medo, a raiva, o seu corpo, seus pensamentos, o ambiente, a espera, o desconhecido, assim como sua história. O que é também particularmente verdadeiro para o contexto hospitalar, entretanto, com a delimitação de que esses sentimentos no momento e contextos atuais estão intimamente relacionados com o processo de saúde-doença. Não é aniquilar a tensão entre as partes constitutivas do vivido de uma enfermidade, uma intervenção cirúrgica ou uma internação. É permitir que a tensão entre as partes seja suficiente ao mesmo tempo para a manutenção da autonomia do paciente, assim como para a continuidade do processo de restabelecimento do seu bem-estar físico e psicológico, que pode significar a continuidade ou a não continuidade do tratamento médico em todos ou alguns de seus aspectos. É uma proposta de descentramento de um modelo de cura romântico que busca o restabelecimento de um estado imaginário anterior de bem-estar para uma proposta de busca incessante da manutenção da autonomia do paciente, regulada pela confiança no saber médico e não por um autoritarismo cego a um suposto poder científico da medicina contemporânea.

Assim como a perspectiva de compreensão da totalidade defendida pela Gestalt-terapia, a psicologia da saúde busca um modelo que compreenda os múltiplos fatores inerentes ao processo de adoecimento (biológicos, psicológicos, sociais e espirituais), rompendo com mode- los lineares e causais da compreensão dos processos de saúde-doença (Ogden, 1996). Segundo Freitas (2009b), em Gestalt-terapia saúde e doença são vistos como dois pólos de um único processo pluridimensional, dinâmico e contínuo. As polaridades saúde e doença não se enquadram dentro de um critério de exclusão, mas se articulam em uma relação complexa e processual. Ser saudável não significa ausência de doenças, nem tampouco, estar doente, ausência de saúde, isto é, "o processo de saúde-doença implica a compreensão dos significados dos sintomas no contexto da personalidade, no contexto de vida, pensamentos e sentimentos dos sujeitos e da cultura" (Freitas, 2009b, p. 71). Contato é sempre contato, não há parâmetros possíveis para se estabelecer o que seja bom ou mau contato. Há que se entender, outrossim, os sentidos de cada expressão e de cada traço do sujeito em seu contexto de vida e não em comparação com uma curva ou gráfico que buscam uma pretensa padronização do campo homem/meio. Buscar aniquilar as tensões inerentes à hospitalização e ao adoecimento é aniquilar o próprio sujeito.

Entender o homem como um campo organismo/meio que se estrutura em uma corporeidade expressiva é, especialmente em nosso contexto, falar de alguém que sofre sendo seu corpo material, visível e sensível à dor, ao toque, ao olhar do outro, ao cheiro que se desprende, ao processo de transformação física, aos sentimentos que dele e com ele vivencia.

Abrir-se a esta possibilidade é permitir uma compreensão de que frente ao adoecimento estamos expostos à ressignificação existencial. Uma organização de novos sentidos para essa existência no ambiente hospitalar é facilitada por meio do contato psicológico, pela mútua atitude do encontro Eu-Tu. Entende-se que o diálogo possibilita que a pessoa seja percebida como um ser relacional e considerada na sua totalidade, dentro do seu contexto existencial aqui-e-agora, que é aquele da doença, da internação, da intervenção médica, da espera e/ou da cirurgia. O diálogo é a busca de novos sentidos que advém desta experiência, geralmente destruíndo sentidos antes já-constituídos. É a busca de novos sentidos existenciais a partir dessa nova história já que o doente não é apenas

um organismo acometido de infecções ou patologias, mas se refere a um corpo experienciado por um doente, como um doente, dotado de uma função na relação deste sujeito com o mundo, mas que, apesar de estar doente, é tambem um corpo com história e com possibilidades e perspectivas (Freitas, 2009b, p. 35).

Longe de ser alguém que necessariamente conhece e pensa científica ou tecnicamente sua patologia, o doente é um ser que vive e sente seu corpo e sua doença, o corpo é a extensão de seu projeto existencial humano. Projeto esse que extrapola o ambito hospitalar já que é também 
sua própria subjetividade que mantém articulação constante com os espaços sociais, sendo um corpo-no-mundo (Freitas, 2009b).

A doença é uma facticidade, no entanto, é revestida pelo sentido que o doente, a familia e a equipe atribuem à dor, à enfermidade ou ao tratamento. A doença existe independente da vontade do doente, no entanto, é o sofrimento, a dor e todos os possiveis desdobramentos de se estar hospitalizado e em tratamento que muitas vezes apontam para uma possibilidade de ruptura, entendida aqui como ressignificação, na vida da pessoa:

O corpo doente tem um sentido próprio por nos tirar do habitual, um corpo "esquecido" e, por isso mesmo, vivido. A doença faz-nos lembrar que temos um corpo. A dor rompe com uma história e com um cotidiano, com um "habitual ser". Mas, paradoxalmente, essa história que ao mesmo tempo é surpreendida e forçada a seguir novos rumos, é uma referência para os sentidos da dor, essa intrusa inesperada (Freitas, 2009b, p. 40).

E o psicólogo, é a testemunha ocular e existencial dessa vida e dessa invasão.

\section{Considerações Finais}

O diálogo, no âmbito hospitalar, possui uma estreita afinidade com uma visão humanizada e holística quanto ao cuidado com o cliente, sua família, e às intervenções junto à equipe multiprofissional. O diálogo Eu-Tu por ser uma atitude de abertura e conexão, de sentir e experienciar a relação se revela como um meio de compreender as necessidades de nosso cliente e, acima de tudo, um meio de ajudá-lo a reconhecer as suas necessidades e responsabilizar-se pelas suas escolhas.

A extrema valorização do vivido, do aqui e agora e do campo organismo/meio (cliente/doença/hospital) facilita a atitude fenomenológica de descrição do vivido considerando-o não como um objeto ou um meio para se chegar a um fim um (Eu-Isso), mas como pessoa que é com seus sentimentos, pensamentos, percepções e coautoria do seu mundo e de seus sentidos subjetivos. É uma atitude e uma prática que considera a pessoa como um todo em suas múltiplas dimensões: intrapsíquica e interpessoal, o que conseqüentemente possibilita uma awareness integrativa.

Partindo dessa reflexão defende-se que o alicerce do trabalho do psicólogo hospitalar em uma equipe multidisciplinar é o diálogo em suas três dimensões: corporeidade, presença e inclusão. Ele serve como base para suas intervenções neste contexto, pois, com uma atitude de abertura ao desvelamento da singularidade de cada pessoa, possibilita a construção de novas formas de relacionamento, escolhas e autopercepção em condição de adoecimento e/ou hospitalização. Compreende que a pessoa quer ser encontrada em um nível mais profundo, ou seja, em sua humanidade (Eu-Tu).

A psicologia da saúde nessa perspectiva se diferencia no cuidado multiprofissional, pois considera as necessidades subjetivas e peculiares de cada um que adoece em seu contexto existencial. Reconhece que a hospitalização e a doença afetam as reações afetivas e as transformações na dinâmica existencial do cliente.

O dialogo Eu-Tu/Eu-Isso não é uma técnica, mas uma abordagem com a qual se busca uma prática que vá além dos atributos técnicos e científicos implícitos no dualismo psicofísico corpo/subjetividade alcançando a habilidade interpessoal, ou seja, a habilidade de se importar e de considerar as características humanas envolvidas no cuidado. Por fim confiamos que a introdução da pessoalidade e sua dimensão ontológica no âmbito hospitalar possibilitam o resgate da intersubjetividade e da humanização, nesse espaço moldado pela impessoalidade.

\section{Referências}

Buber, M. (1982). Do diálogo e do dialógico. São Paulo: Perspectiva.

Buber. M. (1974). Eu e tu. São Paulo: Moraes

Castro, D. S. P. (2002). Existência e Saúde. São Bernardo do Campo: UMESP.

Chiattone, E. B. C. (2004). Entrevista: Encontro nacional dos psicólogos na área hospitalar. Revista Prática Hospitalar [online]. Disponível em: www.praticahospitalar.com.br.

Conselho Federal de Psicologia (2009). Funções do Psicólogo Hospitalar. Acesso em 17/08/2009, de http://www.pol.org. $\mathrm{br} / \mathrm{pol} / \mathrm{cms} / \mathrm{pol} /$.

Freitas, J. L. (2005). Ruptura e Sentido na experiência de adoecimento e morte. Tese de Doutorado em Psicologia, Instituto de Psicologia, Brasília, Universidade de Brasília.

Freitas, J. L. (2009a). Reflexões sobre a relação psicoterapêutica: diálogos com Merleau-Ponty. Revista da Abordagem Gestáltica [online], 15(2), 103-107.

Freitas, J. L. (2009b). Experiência de Adoecimento e Morte: Diálogos entre a pesquisa e a Gestalt-terapia. Curitiba: Juruá Editora.

Foucault, M. (2001). O nascimento da clínica. Rio de Janeiro: Forense Universitária.

Hycner, R. (1995). De Pessoa a Pessoa. São Paulo: Summus.

Hycner, R., \& Jacobs, A. (1997). Relação e Cura em GestaltTerapia. São Paulo: Summus.

Lazzaretti, C. T. (2007). Manual de psicologia hospitalar. Curitiba: Unificado.

Merleau-Ponty, M. (1994) Fenomenologia da percepção. São Paulo: Martins Fontes. 
Murray, M., \& Chamberlain, K. (Orgs.) (1999). Qualitative health psychology. London: SAGE.

Ogden, J. (1996). Health Psychology - a Textbook. Buckingham: Open University Press.

Sant'Anna, D. B. (2001). Corpos de Passagem. São Paulo: Estação Liberdade.

Spink. M. J. (1992). Psicologia da saúde: a estruturação de um novo campo de saber. Em Florianita Coelho Braga Campos (Org.), Psicologia e saúde: repensando práticas (pp. 11-23). São Paulo: Hucitec.

Yontef, G. M. (1998). Processo, Diálogo e Awareness. São Paulo: Summus.

Joanneliese de Lucas Freitas - Gestalt-Terapeuta, Professora do CEGEST (Centro de Estudos de Gestalt Terapia de Brasília), Doutora em Psicologia pela Universidade de Brasília, Professora Adjunto da Universidade Federal do Paraná (UFPR). Endereço Institucional: Departamento de Psicologia, Universidade Federal do Paraná, Praça Santos Andrade, 50 - Sala 215 (Ala Alfredo Buffren). CEP 80060.240 - Curitiba, PR. Email: joanne@ufpr.br

Nutty Nadir Stroiek - Psicóloga formada pela Universidade Paulista (UNIP), Especialista em Psicologia Hospitalar pela Faculdade Pequeno Príncipe. Email: nutty.stroiek@uol.com.br

Débora Botin - Psicóloga formada pela Universidade Comunitária Regional de Chapecó (UNOCHAPECÓ), Especialista em Psicologia Hospitalar pela Faculdade Pequeno Príncipe. Email: deborabotin@ hotmail.com

Recebido em 05.09.10

Primeira Decisão Editorial em 27.09.10

Aceito em 18.11.10 